\title{
Transport delay assessment at unsignalized intersections feeding focal points
}

\author{
Anton Zedgenizov ${ }^{1 *}$, Aleksandr Lipenkov ${ }^{2}$, and Bogdan $\mathrm{Kim}^{1}$ \\ ${ }^{1}$ Department of Oil and Gas Engineering, Irkutsk National Research Technical University, 83, \\ Lermontov str., Irkutsk, 664074, Russia. \\ ${ }^{2}$ Department of Transportation, Nizhny Novgorod State Technical University named after R.E. \\ Alekseev, 24, Minin str., Nizhny Novgorod, 603950, Russia.
}

\begin{abstract}
The article discusses the issues of assessing the delays connected with the transport service of people visiting focal points (FPs) by individual transport (IT). The necessity of using a mathematical approach when assessing delays is proved. The factors influencing transport delays when driving through unsignalized intersections are presented. An integrated mathematical model is derived, which makes it possible to estimate the load factor at unsignalized intersections. This model is based on parameters that reflect transport demand and throughput capacity of an unsignalized intersection. The main parameters required for assessing the capacity of the minor road at an unsignalized intersection are described. An integrated mathematical model is offered that allows estimating the delay of individual transport users leaving the territory (parking lot) of the focal point. The authors elaborate recommendations for the practical application of the considered mathematical models while organizing transport services for focal points visitors using individual transport.
\end{abstract}

\section{Introduction}

The modern city and its influence zone consist of independent focal points differentiated by type, purpose, scale, type of ownership, area, departmental affiliation and other criteria. The fact that the diameter (extension) of modern urban agglomerations can account for tens of kilometers (the Paris agglomeration is about $80 \mathrm{~km}$, the Moscow one $-80 \mathrm{~km}$, the extension of Volgograd is $90 \mathrm{~km}$, etc.) conditions the urgent necessity of using high-speed transport systems when servicing these focal points. Development of high-speed systems of mass passenger transport and, which is especially important, of connection hubs, makes it possible to arrive at remote FPs with very low delay indicators corresponding to urban planning norms [3]. However, when it comes to transport services for suburbanized territories, as well as for FPs requiring the use of individual transport (IT), it is necessary to provide for an appropriate transport infrastructure that can meet the demand for parking within the walking distance from the desired FP. Otherwise, such a FP may lose its commercial appeal and, accordingly, have lower transport demand.

\footnotetext{
*Corresponding author: azedgen@gmail.com
} 


\section{Materials and methods}

It is important to take into account that when visiting the FP by IT, the key aspect is the total time spent on arriving at the FP. In simplified form, the chain of actions of a FP visitor using IT can be represented as the following sequence: entering the territory (parking lot) of the FP through the feeding intersection from the street and road network (SRN) of transit traffic; looking for a parking space; approaching the nearest feeding intersection (when visiting large FPs); exit from the territory (parking lot) of the FP through the feeding intersection to the adjacent SRN. Entrance to the territory of the FP is usually not very difficult and in many cases is practically unlimited, with the exception of those cases when the territory (parking lot) of the FP is packed. The time spent on looking for a parking space depends on many factors, first of all, the availability of free spaces, the duration of parking, the convenience of movement and navigation around the parking area, etc; it requires a particular study. The time required to leave the territory (parking lot) of the FP is of greatest interest, since it depends on the ratio of the intensity of IT trying to leave the FP to the throughput capacity of the feeding intersection. Such a ratio is usually called the traffic load factor (coefficient) in the transport science. As a rule, feeding intersections are unsignalized intersections and in the case of high intensity of transit traffic flow having the priority over the considered one, the number of permitted traffic directions is reduced. Thus, the traffic load factor can be estimated on the basis of the following integrated mathematical model for estimating [1]; in its numerator there is intensity of the traffic flow leaving the FP, and in its denominator - the throughput capacity of the studied road:

$$
z=\sum_{i=1}^{n} \frac{E_{F P} \cdot \frac{d_{i t}}{P_{i t}} \cdot k_{c h}^{d e p} \cdot k_{d}}{\left(\frac{3600}{t_{f}} \cdot e^{-\frac{q_{p}}{3600}\left(t_{g}-\frac{t_{f}}{2}\right)}\right) \cdot\left(\prod_{j=1}^{m} 1-\frac{N_{02 j}}{C_{02 j}}\right) \cdot\left(\prod_{j=1}^{m} 1-\frac{N_{03 j}}{C_{03 j}}\right)}
$$

where $E_{F P}$ - transport demand, persons per hour; $q_{p}$ - intensity of the first-rank traffic flow conflicting with the movement direction in question, vehicles per hour; $k_{d}$ coefficient of the traffic flow proportion distributed between intersections of the given FP (at one intersection $k_{d}=1$ ); $k_{c h}{ }^{d e p}$ - coefficient of daily irregularity on departure; $n$ - number of traffic flows in the traffic group; $t_{g}$ - average boundary zone, sec.; $t_{f}$ - average following distance, sec.; $N_{02 j}$ - intensity of the second-rank traffic flow conflicting with the movement direction in question, vehicles per hour (it is excluded in the absence of it); $N_{03 j}$ - intensity of the third-rank traffic flow conflicting with the movement direction in question, vehicles per hour (it is excluded in the absence of it); $c_{02 j}$ and $c_{03 j}$ - throughput capacity of the second- and third-rank traffic flows, respectively, that conflict with the traffic flow in question, vehicles per hour (it is excluded in the absence of it); $m$ - number of the second- and third-rank traffic flows, respectively, that conflict with the traffic flow in question.

The given model presents the intensity of the traffic flow leaving the FP through the transport demand $[1,14,15]$ and several parameters characteristic of the process of visiting FPs by IT users. The denominator shows the throughput capacity of the minor road at an unsignalized intersection with regard to the intensity of the traffic flow that is prior to the flow in question. Besides, the average boundary zone is of importance as it reflects the possibility of the passage of a vehicle standing in the queue.

The delay of vehicles at unsignalized intersections is presented in some Russian and foreign scientific works $[2,4,5,6,7,8,9,10,11,12,13]$ and, in particular, can be determined by the expression [10]: 


$$
d=\frac{3600}{c_{t}}+900 T\left[\left(\frac{N}{c_{t}}-1\right)+\sqrt{\left(\frac{N}{c_{t}}-1\right)^{2}+\frac{3600 / c_{t} \cdot N / c_{t}}{450 T}}\right]+5
$$

where $c_{t}$ - throughput capacity of the definite traffic flow, units per hour; $T$ - time during which the throughput capacity was evaluated and during which the increased traffic intensity is possible, hours; $N$ - intensity of the definite traffic flow, units per hour.

\section{Results}

Having regard to expressions 1 and 2 it is possible to present the integrated model of delay assessment at an unsignalized intersection:

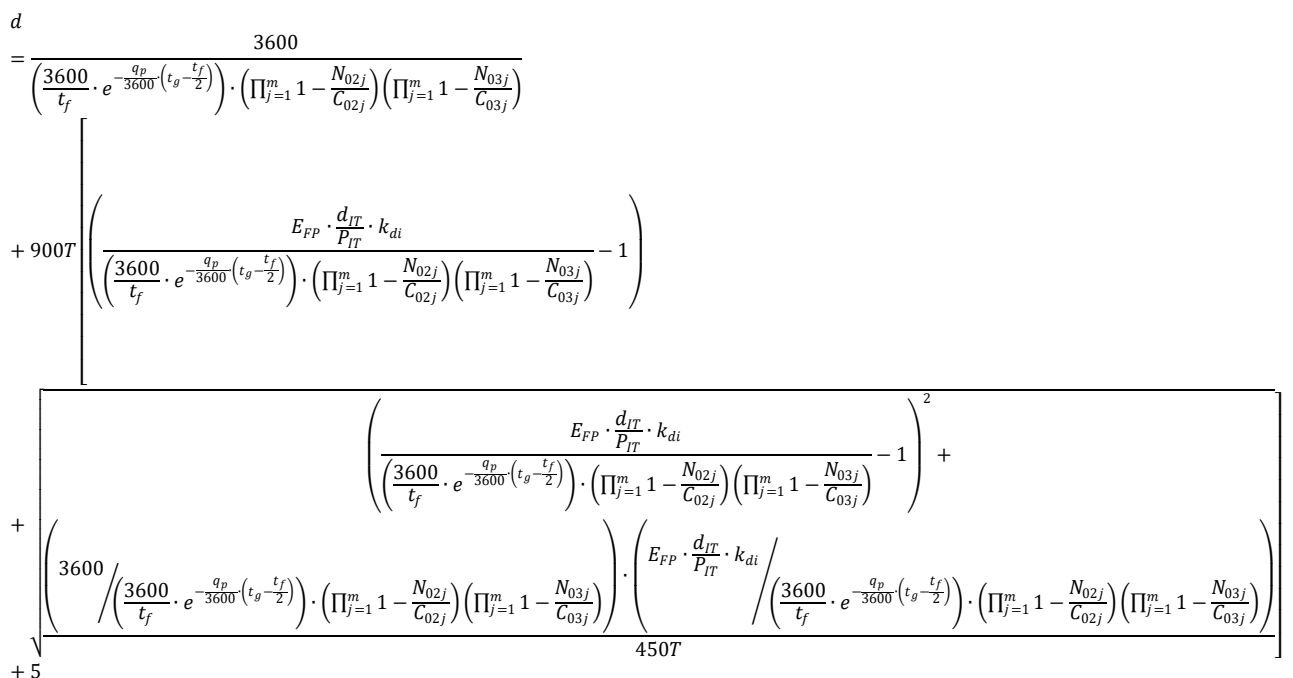

\section{References}

1. Zedgenizov A.V. Assessment of the quality of traffic management on the basis of transport demand: monograph. - Irkutsk: Publishing house of INRTU - 196 p. (2019)

2. Management of road traffic in cities: textbook / ed. by O.D. Shelkov. M.: Akademkniga, 143 p. (1995)

3. Code SP 42.13330.2016. Urban planning. Planning and Development of Urban and Rural Settlements, revised edition of SNiP 2.07.01-89. - Moscow, Ministry of Construcion of RF, - 94 p. (2016)

4. Ashworth R. A note on the selection of gap acceptance criteria for traffic simulation studies / Transportation Science Vol. 2, pp. 171 - 175 (1968)

5. Brilon W., Koenig R., Troutbeck R.J. Useful Estimation Procedures for Critical Gaps / Proc. of the third international Symposium on Intersections Without Traffic Signals. Portland, Oregon, U.S.A., pp. 71 - 87. (1997)

6. Ashworth R. The analysis and interpretation of gap acceptance data / Transportation Science Vol. 4, pp. 270 - 280. (1970)

7. Brilon, W.: Weiterentwicklung der Berechnungsverfahren für Knotenpunkte ohne Lichtsignalanlagen in der Bundesrepublik Deutschland. In: Internationa-len Workshop Kotenpunkte ohne Lichtsignalanlagen / Tagungsunterlagen, Bochum Maerz (1988)

8. Greenshields B.D., Shapiro D., Ericksen E.L. Traffic Performance at Urban Street Intersections. Technical Report No. 1, Yale Bureau of Highway Traffic (1947) 
9. Highway Capacity Manual 2000. - Transportation Research Board, National Research Council. - Washington, D.C., USA, - 1134 p. (2000)

10. Highway Capacity Manual 2010. - Transportation Research Board, National Research Council. - Washington, D.C., USA,- 1134 p. (2010)

11. Thill Jean-Claude, Thomas I. Toward Conceptualizing Trip-Chaining Behavior: A Review // Geographical Analysis.- Vol. 19, № 1. - P. 1-17. (1987)

12. Thomas Richter. Planung von Autobahnen und LandstraBen // Springer Fachmedien Wiesbaden (2016)

13. Tom V. Mathew, K.V. Krishna Rao. Introduction to Transportation Engineering // TRIP GENERATION NPTEL. (2006)

14. Trip Generation Handbook, 2nd Edition: An ITE Recommended Practice. Washington, DC: ITE, (2004)

15. Trip Generation, 8th Edition. Washington, DC: Institute of Transportation Engineers (ITE). (2008) 